International Journal of Biology, Pharmacy and Allied Sciences (IJBPAS) 'A Bridge Betuen Caboratory and QRando'

WWW.ibpas.com

COMPARATIVE EVALUATION OF IPS EMPRESS MATERIAL USED FOR FIXED PARTIAL PROSTHESIS PLACED ON VITAL \& NON-VITAL ABUTMENTS ON THE PERIODONTAL STATUS - A TWO YEAR RETROSPECTIVE FOLLOW-UP

\title{
SHETTY $\mathbf{S}^{1 *}$, SHETTY $\mathbf{K}^{2}$, WALI $\mathbf{O}^{3}$, SAIT $\mathbf{R}^{4}$, ALZAHARANI $\mathbf{R}^{5}$ AND SHEIKH KH ${ }^{6}$
}

1: BDS, MDS (Periodontics), FICOI, Associate Professor, Dentistry Program, IBN Sina National College of Medical Sciences, Jeddah, KSA

2: BDS, MDS (Prosthodontics), FICOI, Associate Professor, Dentistry Program, IBN Sina National College of Medical Sciences, Jeddah, KSA

3: DDS, M.Sc. \& Swedish Board Certified In Periodonology and Dental Implants, Perio-Prosth Fellowship, Vice Dean, Dentistry Program, IBN Sina National College of Medical Sciences, Jeddah, KSA

4: BDS; Intern, Dentistry Program, IBN Sina National College of Medical Sciences, Jeddah, KSA

5: BDS, Intern, Dentistry Program, IBN Sina National College of Medical Sciences, Jeddah, KSA

6: B. Sc, M.Sc. (Statistics), Quality Assurance Center, IBN Sina National College of Medical Sciences, Jeddah, KSA

*Corresponding Author: Shreya Shetty: E Mail: drshreyak@gmail.com; Phone: +966 26374566

Received $13^{\text {th }}$ June 2020; Revised $15^{\text {th }}$ July 2020; Accepted $12^{\text {th }}$ Aug. 2020; Available online $1^{\text {st }}$ May 2021 https://doi.org/10.31032/IJBPAS/2021/10.5.5468

ABSTRACT

\section{Objective:}

A sound periodontium is critical for the long term success of fixed prostheses. These prostheses are often prepared on vital teeth and non-vital as abutments. Endodontically treated teeth (non vital abutments) have often been looked upon with doubt as suitable abutments. Among the popular esthetic materials in use today, IPS empress is a popular choice in fixed prosthodontics. The present study aimed to assess the long term clinical and radiographic effects and tissue responses when IPS empress material was used in FPD placed on vital and non-vital abutment teeth on the periodontal parameters. 


\section{Methodology:}

Following ethical committee approval, the study group comprised of 23 abutment teeth; 13 vital and 10 non vital, in 14 systemically healthy patients (6 males and 8 females) aged between 18 - 45 years who had received 3 unit fixed prosthesis fabricated using IPS empress material having equigingival margins. The following parameters were assessed at the time of bridge placement and 2 year follow up - CAL, Probing depth, Distance between CEJ/ cervical crown margin and alveolar crest of the abutment teeth (radiograph).

Results: Statistical analysis carried out by SPSSV22 software revealed significant changes in clinical parameters $(\mathrm{P}<0.05)$ and no significant changes in radiographic parameters $(\mathrm{p}>0.05)$ from the time of bridge placement till the 2 year follow up. However, significant differences were observed between vital and non vital abutments at the end of the $1^{\text {st }}$ year only with regard to probing depth and $\mathrm{CAL},(\mathrm{p}<0.05)$ but not with radiographic parameters. $\mathrm{p}>0.05)$.

\section{Conclusion:}

There seemed to be favorable responses of the periodontal tissues to IPS material used on the abutments of FPDs with no significant difference between vital and non-vital abutments in the long term follow-up.

Keywords: vital abutments, non-vital abutments, periodontal status, bone loss, IPS empress,

\section{FPD}

\section{INTRODUCTION}

Fixed prosthesis (FPD) is one of the most popular treatment options available today where the dental implant is relatively or totally contraindicated [1]. The abutments used for FPDs may be vital or non-vital and the choice of abutment and long term stability largely depends on sound periodontium [2]. Most often, all surfaces of abutments are prepared to act as retainers of the fixed partial denture. Postcementation hypersensitivity in these abutments is a common complaint among patients receiving fixed prosthesis with vital abutments. Post- cementation sensitivity rates varied widely in clinical studies ranging from a low of $3 \%$ to a high of $34 \%$ [3].

Endodontically treated teeth are commonly required to serve as abutments for crowns, fixed partial dentures, or removable partial dentures. Many clinicians are of the opinion that endodontically treated teeth do not serve as well as vital teeth [4]. However some researchers believe that with appropriate preparation designs, endodontically treated teeth can serve well as abutments for crowns. Wegner et al [5] concluded that the endodontically treated teeth restored with endodontic posts and crowns had a good survival rate $(92.7 \%)$ 
when observed for a 5 year period. In some fixed partial denture designs, such as long span cases, the use of endodontically treated teeth may be contraindicated.

On the other hand, evidence has also revealed that the survival of the vital pulp in teeth restored with a single-unit metal ceramic crown (CMC) was significantly higher than those serving as an abutment of a fixed-fixed bridge. However, it has also been observed that maxillary anterior teeth used as bridge abutments had a higher rate of pulpal necrosis than any other tooth types [6] Backer et al (2007) concluded that endodontically treated abutments resulted in more FDP failures than vital abutments [7].

Selection of a suitable abutment for fixed prosthesis is critical as FPDs transmit forces through the abutments to the periodontium. Successful selection of abutments for fixed partial dentures requires sensitive diagnostic ability and a thorough knowledge and understanding of anatomy, ceramics, the chemistry and physics of dental materials, metallurgy, Periodontics, phonetics, physiology, radiology and the mechanics of oral function [8] which is crucial in the development of treatment plan with predictable prognosis. It is paramount to focus on the qualities of FPDs and crowns in order to reduce the periodontal inflammation and ensure long term prognosis of the prosthesis as periodontal health governs FPD survival to a large extent. In this regard, the type of material used also plays an important role in determining the long term periodontal health. Studies have forced clinicians and researchers to focus on the qualities of FPDs and crowns in order to reduce the periodontal inflammation and ensure longevity of the prosthesis [9-12].

Over the last few decades the field of dental ceramics has evolved rapidly, both in material properties and manufacturing techniques. Among these advancements is the introduction of glass-ceramics, which are both highly esthetic and possess exceptional mechanical properties. One such material is the IPS e.Max line (Ivoclar Vivadent, Schaan, Liechtenstein), which comes in two forms, a block that can be milled in a CAD/CAM system (IPS_e.Max CAD) and an ingot used for pressable crown fabrication following the lost wax technique (IPS_ e.MaxPress). Due to the recent nature of these materials research into the material science, mechanical and optical properties, and clinical applications is still ongoing [13].

A literature review on the longevity and clinical performance of IPS -Empress restorations suggested that these crowns were not recommended for the posterior region [14]. In fact, Holland et al [15] reported that IPS Empress 2 may be used to 
fabricate 3unit bridges upto second premolar. Whether this has any bearing on the periodontal status is unclear. Studies of IPS e.Max CAD have been limited in scope, partially due to the limited time the material has been available on the market. Several studies have shown promising short-term and medium-term survivability for single unit crowns and initial results for implementation for inlays and onlays is also promising. To date there is insufficient long-term survival data available.

Thus, the aim of the present cross sectional study was to assess the effect of IPS impress material used in FPD on the periodontal status of vital and non-vital abutment teeth over a 2 year period.

\section{MATERIALS AND METHODS}

Following approval from the institutional Ethical Committee at ISNC, Jeddah, nearly 200 patients treated with 3 unit FPDs in the period between January 2017 and December 2018 were screened. Of these, 23 abutment teeth (10 non vital and 13 vital) in 14 patients were selected for the study based on the following inclusion criteria:

1) Adults who were systemically healthy, non-smokers, and who had 3 unit FPDs using IPS empress for atleast two years and
2) Abutment teeth that had equigingival margins with plaque and gingivalindices less than $10 \%$.

Informed consents were obtained from the enrolled subjects after explaining the nature of the study and possible risks involved.

Clinical and radiographic measurements were made on the abutment teeth at baseline, following placement of bridge and at 1 and 2 year follow up visits with a UNC 15 periodontal probe as follows:

1. Probing depth( facial and lingual)

2. Clinical attachment level (CAL) (facial and lingual)

A total of 6 measurements, 3 each on the facial and lingual surfaces and an average of these were used as a final value.

The following measurements were made on the radiographs on the abutment teeth using grids.

1. Distance from CEJ to alveolar crest. (baseline)

2. Distance from cervical margin of crown to alveolar crest. (FPD placement and follow up)

Care was taken to ensure that the radiographic techniques and the radiographs were standardized to maintain homogeneity in measurements.

The linear distances in two dimensions were measured using the following mathematical formula:

\section{$\frac{\text { Actual distance between two points (grid) }}{\text { Measured distance between two points (grid) }}=\frac{\text { Actual distance between two points (anatomic) }}{\text { Measured distance between two points (anatomic) }}$}


The distance measured was between 2 points - cementoenamel junction/ crown margin to alveolar crest.

The patients were given appropriate oral hygiene instructions to ensure maintenance of low plaque scores throughout the duration of the study.

\section{RESULTS}

Statistical analysis was carried out using SPSSV22 software. Since the data was normal, paired ' $t$ ' tests were used to assess the differences in the means of the clinical parameters of each material at the different time intervals.

\section{IPS Empress on Vital Abutment (Table 1}

\section{A \& B)}

The vital abutment teeth receiving IPS empress crowns revealed a statistically significant reduction in probing depth from time of placement to post 2 year follow up period. $(\mathrm{P}<0.005)$ but not with regard to CAL $(\mathrm{P}>0.05)$. However, no significant changes were observed in the bone levels seen in the radiographs in the 2 year period.
IPS Empress on Non-Vital Abutment (Table 2 A \& B)

The non-vital abutment teeth receiving IPS empress crowns revealed a statistically significant reduction in probing depth and CAL from time of placement to post 2 year follow up period $(\mathrm{P}<0.005)$. However, no significant changes were observed in the bone levels seen in the radiographs in the 2 year period $(\mathrm{P}>0.05)$.

\section{IPS Empress -Vital v/s Non-Vital:}

\section{(Table 3)}

Comparison of the clinical parameters between the vital and non-vital abutments revealed significant differences in probing depth at the end of 1 year $(p<0.05)$ with non- vital abutments showing greater reduction than vital abutments. Similarly, significant differences were observed with regard to CAL at 6 months, 1year and 2 years $(p<0.05)$ with non-vital abutments showing more attachment gain than vital abutments. However, no significant differences were observed in the radiographic bone levels. $(\mathrm{p}>0.05)$

\section{Vital}

Table 1 A:Paired Samples Statistics

\begin{tabular}{|ll|c|c|c|c|}
\hline & & Mean & N & Std. Deviation & Std. Error Mean \\
\hline Pair 1 & PD P-3 & 1.785 & 13 & .4413 & .1224 \\
& PD P-4 & 1.454 & 13 & .3821 & .1060 \\
Pair 2 & CAL P3 & .623 & 13 & .7748 & .2149 \\
& CAL P4 & .523 & 13 & .4604 & .1277 \\
& RBL P3 & $1.508^{\mathrm{a}}$ & 13 & .4856 & .1347 \\
& RBL P4 & $\mathbf{1 . 5 0 8}^{\mathrm{a}}$ & 13 & .4856 & .1347 \\
\hline
\end{tabular}

a. The correlation and t cannot be computed because the standard error of the difference is 0 . $\mathrm{P}-3$ at the time of bridge cementation; $\mathrm{P}-4$ at the end of 2 years 
Table 1 B

\begin{tabular}{|c|c|c|c|c|c|c|}
\hline & \multirow[b]{2}{*}{ Mean } & \multirow[b]{2}{*}{$\begin{array}{c}\text { Std. } \\
\text { Deviation }\end{array}$} & \multirow[b]{2}{*}{ t } & \multirow[b]{2}{*}{ df } & \multirow[b]{2}{*}{$\begin{array}{l}\text { Sig. (2- } \\
\text { tailed) }\end{array}$} \\
\hline & & & & & & \\
\hline & $\begin{array}{l}\text { PD P-3(F/L) - } \\
\text { PD P-4(F/L) }\end{array}$ & .3308 & .3276 & 3.641 & 12 & .003 \\
\hline Pair 2 & $\begin{array}{l}\text { CAL P } 3 \text { - } \\
\text { CAL P } 4\end{array}$ & .1000 & .5354 & .673 & 12 & .513 \\
\hline
\end{tabular}

Non-Vital

Table 2 A

\begin{tabular}{|c|c|c|c|c|c|c|}
\hline & & Mean & $\begin{array}{c}\text { Std. } \\
\text { Deviation }\end{array}$ & t & df & $\begin{array}{l}\text { Sig. (2- } \\
\text { tailed) }\end{array}$ \\
\hline $\begin{array}{c}\text { Pair } \\
1\end{array}$ & $\begin{array}{l}\text { PD P3 } \\
\text { PD P4 }\end{array}$ & .3750 & .5133 & 5.268 & 51 & .000 \\
\hline $\begin{array}{l}\text { Pair } \\
2\end{array}$ & $\begin{array}{l}\text { CAL P3 } \\
\text { CAL P4 }\end{array}$ & .4519 & .5710 & 5.707 & 51 & .000 \\
\hline $\begin{array}{c}\text { Pair } \\
3\end{array}$ & $\begin{array}{l}\text { RBL P3 } \\
\text { RBL P4 }\end{array}$ & -.0962 & .3965 & -1.749 & 51 & .086 \\
\hline
\end{tabular}

$\mathrm{P}-3$ at the time of bridge cementation

$\mathrm{P}-4$ at the end of 2 years

Table 2 B: Paired Samples Statistics

\begin{tabular}{|cc|c|c|c|c|}
\hline & & Mean & N & Std. Deviation & Std. Error Mean \\
\hline Pair 1 & phase 3(F/L) & 2.400 & 10 & .9068 & .2867 \\
& phase 4(F/L) & 1.500 & 10 & .5270 & .1667 \\
Pair 2 & phase 3 & 1.900 & 10 & 1.4298 & .4522 \\
& phase 4 & 1.200 & 10 & .7149 & .2261 \\
Pair 3 & Phase3 & 1.400 & 10 & .5164 & .1633 \\
& Phase 4 & 1.300 & 10 & .4830 & .1528 \\
\hline
\end{tabular}

Table 3: Parametric test - t-test for independent variables vital v/s non-vital abutments

\begin{tabular}{|c|c|c|c|c|}
\hline & $\mathrm{t}$ & df & Sig. (2-tailed) & Mean Difference \\
\hline PDbaseline & $\mathbf{2 . 6 2 5}$ & $\mathbf{2 1}$ & .016 & .6754 \\
\hline PD - 6months & -1.722 & 21 & .100 & -.4492 \\
\hline PD - 1 year & -2.200 & 21 & $.039^{*}$ & -.6292 \\
\hline PD -2 years & -.209 & 21 & .836 & -.0392 \\
\hline CALbaseline & $\mathbf{3 . 2 3 2}$ & 21 & $.004^{*}$ & .5023 \\
\hline CAL - 6months & -2.942 & 21 & $.008^{*}$ & -.9723 \\
\hline CAL - 1year & -2.760 & 21 & $.012^{*}$ & -1.2838 \\
\hline CAL- 2 years & -2.749 & 21 & $.012^{*}$ & -.6746 \\
\hline RBLbaseline & 1.495 & 21 & .150 & .3685 \\
\hline RBL- 1year & .536 & 21 & .597 & .1123 \\
\hline RBL- 2years & 1.044 & 21 & .308 & .2123 \\
\hline
\end{tabular}

\section{DISCUSSION}

There is a growing popularity of the newer esthetically and biologically compatible materials used in fixed partial dentures today. Although PFM (porcelain fused to metal) has been a popular choice for a long time, newer esthetic materials such as IPS empress (E-max) and zirconia are gradually replacing it. IPS empress is especially used in the anterior esthetic zone and is a popular choice. 
Vital teeth as abutments pose a few disadvantages like development of periapical pathology ${ }^{16}$. In addition, sensitivity to hot or cold stimulation may be an occasional, but unwanted consequence of a newly cemented crown or fixed partial denture. Because of sectioning of dentinal tubules, a certain degree of pulpal trauma is inevitable during tooth preparation. Completely avoiding sensitivity is impossible [3].

The integrity of the tooth might be important for endodontically-treated teeth, since a treated tooth might become dry and weak when compared to vital teeth [17]. It was the intention ofthe current study to determine the periodontal integrity of the treated teeth.

Alsinaidi et al 2014 [2] indicated that in subjects with fixed partial dentures, the abutment teeth are more prone to periodontal inflammation than the nonabutment teeth. Additionally, the individual's age, duration of insertion of fixed partial dentures and location of the crown margins affect the periodontal health of the abutments. Studies have also suggested that the type of restorative material used in the prosthesis may affect the periodontal status of teeth $[\mathbf{1 8 , 1 9 ]}$.

This study was designed to assess the periodontal status of a group of Saudi adult patients following the insertion of FPDs with IPS empress material on both vital and non-vital abutments. Such an evaluation of the oral health status of the patients is essential to establish effective maintenance programs.

It was decided to include only bridges in which the crown margins were equigingival. Only 3 unit bridges were included in order to standardize the occlusal load on the abutments and keep it uniform. Bridges with multiple units would have further led to variations in clinical and radiographic parameters owing to variations in the load bearing capacity of the abutments. This made it easier to standardize the study population and perform appropriate measurements both clinically and radiographically as the landmarks could be easily determined for linear measurements.

Biocompatibility and chemical durability are highly important properties in dental materials. De Baker [7] reported that it is the baseline periodontal health that determines the long term periodontal success of a fixed restoration irrespective of margin configuration. Several authorsalso concluded that the type of restorative material had no effect on the health of periodontal tissues $[\mathbf{1 8 - 2 1 , 2 3 ]}$.

On the basis of such varying evidences, it was decided to assess the effects of IPS empress used in fixed prosthesis on the periodontal status of vital and non-vital 
abutments by evaluating the clinical and radiographic parameters.

Our results revealed that clinically, IPS empress crowns on both vital and non vital abutment teeth showed significant improvement in clinical parameters over the 2year follow -up period with little or no change in radiologic parameters. These encouraging results strongly suggest that newer materials show definite promise for long term use.

However, a comparison of the vital and non-vital abutments revealed significantly lower probing depths at the end of 1year, as well as lower CAL at the end of 6months, 1year and 2 years in the non-vital abutments compared to the vital abutments with no significant changes observed radiographically.

Although a vital pulp and optimal periodontal health ensures the health of the periradicular areas, not much evidence is available with regard to the long term survival of a vital abutment serving an FPD. Many researchers have suggested that the long term prognosis of such abutment teeth may be guarded, yet, these teeth serve well if the health of the periodontium is maintained. However, the risk of root caries, post cementation sensitivity and pulpal necrosis still remains with the use of these teeth as abutments. Nevertheless, the type of material used for FPD seemed to have no effect on the periodontal health or the vitality of the abutment teeth which is contrary to the findings of Al Wahadini et al (2006) who concluded that teeth with IPS Empress crowns had poorer periodontal health and more clinically evident plaque than uncrowned teeth [19].

A study conducted by the same authors also concluded that there were no differences in the periodontal status between vital and non-vital abutment teeth in the various types of esthetic FPD bridges [24, 25].

\section{Limitations}

A larger sample size on a larger cross section of the population including other esthetic materials and a comparative evaluation is recommended for more authenticity in results.

\section{CONCLUSION}

Within the limitations of the study, overall, the type of material used in FDP, IPS empress in this case, may not influence the long term periodontal status of the abutment as they showed improvement clinically.

\section{CONFLICT OF INTEREST: Nil SOURCE OF FUNDING}

The study has not been funded by any party or organization as such, and any expenses incurred for the same were minimal and borne by the researchers and the institute.

\section{REFERENCES}

[1] Hebel K, Gajjar R, Hofstede T. Single-tooth replacement: bridge vs. 
implant-supported restoration. Can Dent Assoc 2000; 66: 435-8.

[2] Aljoharah Al-Sinaidi, Reghunathan S. Preethanath. The effect of fixed partial dentures on periodontal status of abutment teeth. The Saudi Journal for Dental Research (2014) 5, 104-108.

[3] K. Kamalakanth Shenoy, Anas B. Post-Cementation Sensitivity in Vital Abutments of Fixed Partial Denture: A Review. Sch. J. App. Med. Sci., 2017; 5(3D): 1009-1013.

[4] Goga R, Purton DG. The use of endodontically treated teeth as abutments for crowns, fixed partial dentures, or removable partial dentures: a literature review.Quintessence Int. 2007 Feb; 38(2): e106-11.

[5] Pia K. Wegner, Sandra Freitag, Matthias Kern, Survival Rate of Endodontically Treated Teeth With Posts After Prosthetic Restoration Journal of Endodontic, Volume 32, Issue 10, 928 - 931.

[6] Cheung, Gary \& C N Lai, S \& P Y $\mathrm{Ng}$, R. (2005). Fate of vital pulps beneath a metal-ceramic crown or a bridge retainer. International endodontic journal. 38. 521-30. 10.1111/j.1365-2591.2005.00982.x.

[7] De Backer H, Van Maele G, De Moor N, Van den Berghe L.
Survival of complete crowns and periodontal health: 18-year retrospective study. Int J Prosthodont. 2007; 20: 151-158.

[8] Shivakshi Chansoria, Harsh Chansoria " Abutment Selection In Fixed Partial Denture" IOSR Journal of Dental and Medical Sciences (IOSR-JDMS), 2018: 17( 3): 04-12.

[9] Felton D, Kanoy B, Bayne S. Effect of in vivo crown margin discrepancies on periodontal health. J Prosthet Dent 1991; 65: 357-64.

[10] Valderhaug J, Ellingsen J, Jokstad A. Oral hygiene, periodontal conditions and carious lesions in patients treated with dental bridges. A 15-year clinical and radiographic follow-up study. J Clin Periodontol 1993; 20: 482-9.

[11] Ehrlich J, Hochman N. Alterations on crown contour-effect on gingival health in man. J Prosthet Dent 1980; 44: 523-5.

[12] Mishary Almotairy, Fuad Almaghrabi, Abdulrahman Alharthy, Hisham Alrashaid, Hafez Diab and Yousef Shibatalhamad "Effect of Full Ceramic Crown Versus Ceramic Fused to Metal Crown on Periodontal Tissues Health". EC 
Dental Science 17.7 (2018): 10411046.

[13] Willard A and Chu TG. The science and application of ips e.max dental ceramic. Kaohsiung journal of medical sciences 2018; 34: 238-242.

[14] El-Mowafy, Omar \& Brochu, Jean-François. (2002). Longevity and Clinical Performance of IPSEmpress Ceramic Restorations A Literature Review. Journal (Canadian Dental Association). 68. 233-7.

[15] Höland, W \& Schweiger, Marcel \& Frank, M \& Rheinberger, V. (2000). A Comparison of the Microstructure and Properties of the IPS Empress ${ }^{\circledR} 2$ and the IPS Empress ${ }^{\circledR} \quad$ Glass-Ceramics. Journal of biomedical materials research. $53 . \quad 297-303$. $10.1002 / 1097-$ 4636(2000)53:43.0.CO; 2-G.

[16] Y. Ravi Shankar, K. Srinivas, HemChand Surapaneni, S.V. Sudhakar Reddy. Prosthodontic Treatment Using Vital and Non Vital Submerged Teeth: Two Case Reports.Journal of Clinical and Diagnostic Research. 2013 Oct, Vol-7(10): 2396-2399.

[17] DA Tagtekin, G Özyöney, F Yanikoglu. Two-year Clinical
Evaluation of IPS Empress II Ceramic Onlays/InlaysOperative Dentistry, 2009, 34-4, 369-378.

[18] Abidi. Y. A, Jameel. A, Hasan.A and Rashid. S. An Evaluation of Association between Crown Margins \& Materials with the Periodontal Health. JPDAVol. 20 No. 03 July-Sep 2011.

[19] Al-Wahadni AM, Mansour Y, Khader Y.Periodontal response to all-ceramic crowns (IPS Empress) in general practice. Int J Dent Hyg. 2006 Feb; 4(1): 41-6.

[20] Van Brakel R, Meijer GJ, Verhoeven JW, Jansen J, de Putter C, Cune MS. Soft tissue response to zirconia and titanium implant abutments: an in vivo withinsubject comparison. J Clin Periodontol 2012; 39: 995-1001.

[21] Reitemeier B, Hansel K, Walter $\mathrm{MH}$, Kastner C, Toutenburg $\mathrm{H}$. Effect of posterior crown margin placement on gingival health. J Prosthet Dent. . $2002 ; 87: 167-172$.

[22] Christensen GJ. Porcelain-fusedto-metal versus zirconia-based ceramic restorations, 2009. J Am DentAssoc. 2009; 140: 1036-1039.

[23] Kancyper SG, Koka S. The influence of intracrevicular crown margins on gingival health: 
preliminary findings. J Prosthet.

Dent. 2001; 85: 461-465.

[24] Shetty S, Shetty K, Tayeb R, Abdou J, Fetaihi B, Sheikh KH. Comparative Evaluation of Esthetic Materials Used for Fixed Partial Prosthesis Placed On Vital Abutments On The Periodontal Status: A One Year Retrospective Follow-Up. IntHealthc Res J. 2019; 3(5):179-184. https://doi.org/10.26440/IHRJ/030 5.08271

[25] Shetty S, Shetty K, Wali O, Almarshoud L et al. Comparative Evaluation of Esthetic Materials Used For Fixed Partial Prosthesis on the Periodontal Status - A One Year Retrospective Follow-UP. International Journal of Medical Science and Advanced Clinical Research (IJMACR) 2019; 2(2): 84-92. 